\title{
STRATEGI PENGEMBANGAN USAHA MIKRO KECIL MENENGAH (UMKM) KOPI SUKA SANGRAI DI KELURAHAN SUKA ASIH KOTA BANDUNG
}

\author{
DEVELOPMENT STRATEGY OF MICRO SMALL AND MEDIUM ENTERPRISES \\ (UMKM) SUKA SANGRAI COFFEE IN SUKA ASIH VILLAGE BANDUNG CITY
}

\author{
HASBI SALMAN ELLI*, PANDI PARDIAN, NUR SYAMSIYAH, \\ SULISTYODEWI NUR WIYONO ${ }^{2}$
}

Fakultas Pertanian, Universitas Padjadjaran

*Email : hasbi_salman@yahoo.com

\begin{abstract}
ABSTRAK
Kopi merupakan salah satu komoditas perkebunan yang sangat populer dan mendunia. Seiring berjalannya waktu, kopi semakin banyak dikenal dan dibudidayakan di seluruh dunia, termasuk Indonesia. Konsumsi komoditas kopi diproyeksikan akan terus meningkat dari tahun 2016 hingga tahun 2020 mendatang. Hal ini dibuktikan dengan kemunculan kedai-kedai kopi yang tersebar di daerah perkotaan khususnya di kota Bandung. Kenaikan jumlah kedai kopi ini menjadi peluang bagi pelaku bisnis kopi, salah satunya yaitu perusahaan prosesor atau roastery. Perusahaan ini memiliki hubungan langsung dengan kedai-kedai kopi untuk menyuplai biji kopi. UMKM Suka Sangrai merupakan salah satu perusahaan pengolahan pasca panen bagian roastery namun saat ini UMKM Suka Sangrai mengalami penurunan output dan kehilangan penjualan. Munculnya usaha senjenis membuat UMKM Suka Sangrai harus dapat berkembang dan terus berinovasi sehingga dapat bertahan dan bersaing. Desain pada penelitian ini menggunakan desain kualitatif dan teknik penelitiannya studi kasus. Analisis yang digunakan yaitu matriks IFE, EFE, IE, SWOT dan QSP. Matriks IFE dan EFE menunjukkan bahwa perusahaan memiliki kondisi lingkungan internal sedang dan lingkungan eksternal sedang. Matriks $I E$ menunjukkan bahwa perusahaan berada pada posisi tahan dan pertahankan. Strategi alternatif yang dirumuskan dari hasil matriks SWOT dan QSP dengan prioritas pertama adalah melakukan diversifikasi produk dengan membuat produk kemasan-kemasan kecil siap seduh dilengkapi dengan tata cara menyajian untuk meningkatkan potensi penjualan dan menjangkau pasar yang lebih luas.
\end{abstract}

Kata Kunci: Kopi, Penyangraian Kopi, Strategi Pengembangan

\begin{abstract}
Coffee is one of the most popular and worldwide plantation commodities. As time went by, coffee is increasingly known and cultivated throughout the world, including Indonesia. Consumption of coffee commodities is projected to continue to increase from 2016 to 2020. This is evidenced by the emergence of coffee shops that are located in urban areas, especially in the city of Bandung. The increase in the number of coffee shops is an opportunity for coffee business people, one of them is a processor company or roaster. This company has direct links with coffee shops to supply coffee beans. UMKM Suka Sangrai is one of the roaster post-harvest processing companies. Currently, UMKM Suka Sangrai is still experiencing a decline in output and also losing orders. Many existing competitors, UMKM Suka Sangrai must be able to develop and continue to innovate so that they can survive and compete in the market. The design of this study uses qualitative design and research techniques as case studies. The analysis used in this research is the IFE, EFE, IE, SWOT, and QSP matrix. The IFE and EFE matrices show that the company has moderate internal environmental conditions and moderate external environment. IE matrix shows that the company is in a hold and maintain position. An alternative strategy that is formulated from the SWOT and QSP matrix results with the first priority is to diversify the product to increase sales potential.
\end{abstract}

Keywords: Coffee, Roasting Coffee, Strategy Development 


\section{PENDAHULUAN}

Kopi merupakan salah satu komoditas perkebunan yang sangat populer dan mendunia. Kopi berasal dari Afrika tepatnya di daerah Ethiopia. Seiring berjalannya waktu, kopi semakin banyak dikenal dan dibudidayakan di seluruh dunia, termasuk Indonesia. Indonesia merupakan salah satu penghasil kopi arabika dan robusta terbaik serta pengekspor terbesar keempat dunia setelah Kolombia, Vietnam, dan Brazil (Abdul Halik dkk, 2015). Berikut adalah data produksi kopi di Indonesia.

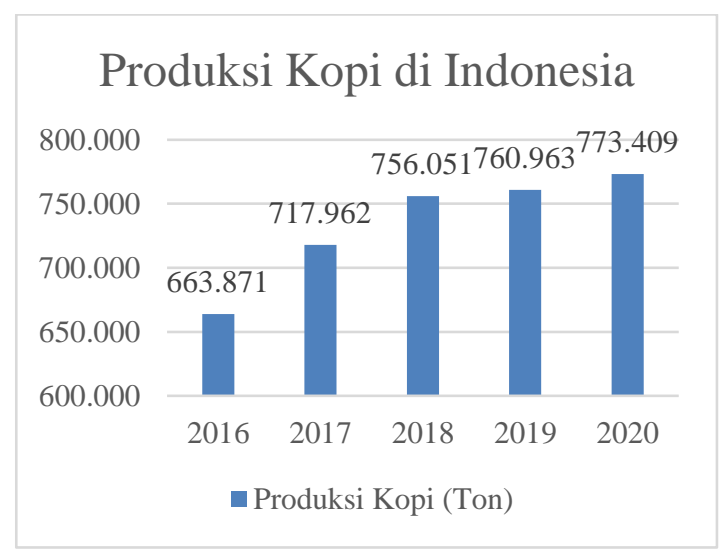

Gambar 1. Produksi Kopi di Indonesia

Sumber : Kementerian Pertanian Republik Indonesia, 2018

Berdasarkan Gambar 1, dapat dilihat bahwa produksi kopi di Indonesia terus meningkat dari tahun 2016 hingga tahun 2020. Seiring berkembangannya zaman, biji kopi dimanfaatkan dan diolah menjadi minuman kopi yang dapat dikonsumsi melalui proses ekstraksi dan penyeduhan yang dilakukan dalam berbagai metode. Rasa yang khas serta aroma yang harum menjadikan kopi sangat cocok untuk dinikmati sambil menemani pekerjaan maupun aktivitas lainnya. Saat ini di Indonesia khususnya di kota-kota besar termasuk Kota Bandung, kopi merupakan minuman yang digemari dan populer dikalangan remaja hingga dewasa. Perlahan-lahan kopi mulai menjadi gaya hidup yang akhirnya membuat konsumsi kopi meningkat. Data kenaikan konsumsi kopi di Indonesia dapat dilihat pada Gambar 2.

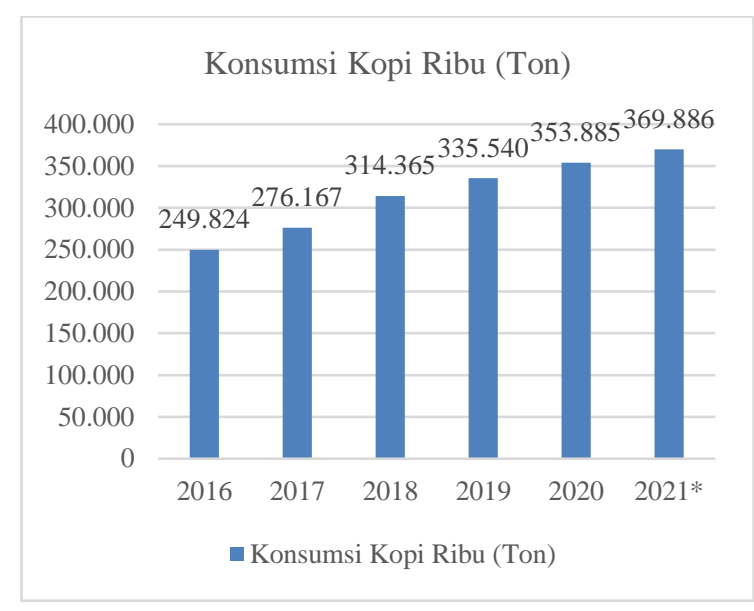

Gambar 2. Konsumsi Kopi di Indonesia Tahun 2016-2021

Sumber : Kementerian Pertanian, 2018

Berdasarkan Gambar 2, konsumsi komoditas kopi akan terus meningkat dari tahun 2016 hingga tahun 2020. Kementerian Pertanian juga memproyeksikan konsumsi kopi di 
Indonesia akan terus meningkat hingga tahun 2021. Peningkatan ini disebabkan oleh melekatnya kopi kedalam kebutuhan serta gaya hidup masyarakat sehari-hari.

Kenaikan jumlah permintaan biji kopi ini menjadi peluang bagi pelaku bisnis olahan kopi, salah satunya perusahaan prosesor atau roastery. Perusahaan ini memiliki hubungan langsung dengan kedaikedai kopi untuk menyuplai biji kopi. Roastery secara singkat adalah proses penyangraian atau pemanggangan biji kopi beras (green bean) menjadi kopi sangrai dengan tingkat kematangan tertentu.

UMKM Suka Sangrai merupakan salah satu perusahaan pengolahan pasca panen bagian roastery yang didirikan oleh Temy Riyadi dengan bentuk perusahaan UMKM. Diawali dari keinginan untuk menyuplai biji kopi berkualitas untuk kebutuhan bisnis kedai kopinya sendiri, lalu berkembang menjadi supplier untuk memenuhi kebutuhan biji kopi kedai kopi lain di berbagai daerah di dalam dan di luar Kota Bandung.

UMKM Suka Sangrai baru berdiri selama 3 tahun, akan tetapi sudah banyak dipercaya oleh konsumen. Bahan baku yang digunakan oleh UMKM Suka Sangrai didapatkan dari beberapa mitra seperti petani, distributor kopi dari berbagai daerah, dan koperasi. Rata-rata permintaan konsumen setiap bulannya saat ini adalah $190 \mathrm{~kg}$ kopi sangrai yang terdiri atas $100 \mathrm{~kg}$ house blend (campuran robusta dan arabika untuk espresso) dan $90 \mathrm{~kg}$ kopi arabika yang terdiri dari jenis speciality dan komersial beans.

Walaupun permintaannya tinggi, kenyataanya saat ini UMKM Suka Sangrai masih mengalami penurunan output dan juga lost sale atau kehilangan order sebesar 20\% sejak tahun 2019 setiap bulannya. UMKM Suka Sangrai hanya dapat memenuhi $80 \%$ dari permintaan keseluruhan konsumennya. Faktor penyebabnya yaitu pemesanan mendadak, ketidaktersediaan bahan baku dan banyak faktor lainnya.

UMKM Suka Sangrai harus dapat berkembang dan terus berinovasi sehingga dapat bertahan dan bersaing di pasaran. Maka, dibutuhkan strategi pengembangan yang tepat untuk dapat membuat UMKM Suka Sangrai bisa bertahan dan bersaing di pasaran. Penting untuk diteliti mengenai Strategi Pengembangan Usaha Mikro Kecil Menengah (UMKM) Kopi Suka Sangrai di Kelurahan Suka Asih Kota Bandung.

\section{METODE PENELITIAN}

Desain yang digunakan dalam penelitian ini adalah desain kualitatif. Desain kualitatif dipilih karena dalam penelitian ini dibutuhkan pendekatan 
individu yang mendalam dan terperinci terhadap setiap informan, agar hasil yang didapatkan dapat valid atau benar (Sugiyono, 2009). Metode yang digunakan dalam penelitian ini adalah studi kasus (Pardian, Esperanza, and Wulandari 2012). Bogdan (1990) dalam Idrus (2009) mendefinisikan studi kasus sebagai kajian yang rinci atas suatu latar atau peristiwa tertentu.

Analisis Matriks IFE (Internal Factor Evaluation).

Menurut David (2006), analisis internal dilakukan untuk mengetahui kekuatan dan kelemahan yang dimiliki oleh perusahaan.

Analisis Matriks EFE (External Factor Evaluation).

Menurut David (2006), analisis eksternal dilakukan untuk mengetahui peluang dan ancaman yang dimiliki oleh perusahaan.

\section{Matriks IE (Internal-External)}

Tahap ini merupakan tahap pencocokan dengan memasukkan hasil pembobotan matriks $I F E$ dan $E F E$ kedalam matriks IE. Menurut David (2006), hal ini bertujuan untuk memperoleh strategi bisnis di tingkat korporat yang lebih detail. Matriks IE merupakan hasil penggabungan antara matriks $I F E$ dan matriks $E F E$ ke dalam matriks yang terdiri dari sembilan sel.
Matriks IE memiliki tiga implikasi utama yang mempunyai dampak strategi berbeda, yaitu Growth and Build (tumbuh dan bina) berada dalam sel I, II, IV. Strategi yang cocok adalah intensif seperti penetrasi pasar, pengembangan pasar atau pengembangan produk, dan strategi terintegrasi seperti integrasi ke belakang, integrasi kedepan dan integrasi horizontal. Hold and Maintain (pertahankan dan pelihara) dilakukan untuk sel III, V danVII. Strategi umum dipakai yaitu strategi penetrasi pasar dan pengembangan produk, dan yang terakhir adalah Harvest or Divest (panen atau divestasi) dipakai untuk sel VI, VIII, IX. Strategi umum yang dipakai adalah strategi divestasi, strategi diversifikasi konglomerat, dan strategi likuidasi.

\section{Matriks SWOT (Strength, Weakness, Opportunities, Threats)}

Merupakan alat pencocokan yang digunakan dalam mengidentifikasi berbagai faktor secara sistematis untuk merumuskan strategi perusahaan. Matriks ini menggambarkan bagaimana peluang dan ancaman eksternal yang dihadapi perusahaan dapat disesuaikan dengan kekuatan dan kelemahan yang dimilikinya. 
Matriks QSP (Quantitative Strategic

\section{Planning)}

Analisis matriks QSP digunakan untuk mengevaluasi strategi secara obyektif berdasarkan faktor-faktor sukes utama internal-eksternal (IE) yang telah diidentifikasi pada tahap sebelumnya.

\begin{abstract}
Hasil Analisis Matriks IFE
Matriks IFE menggambarkan kondisi internal perusahaan yang terdiri atas kekuatan dan kelemahan yang dihitung berdasarkan bobot dan rating yang didapat dari rata-rata kuisioner yang diisi oleh 2 orang responden yaitu owner, dan manajer.
\end{abstract}

\section{HASIL DAN PEMBAHASAN}

\section{Tabel 1. Hasil Analisis Matriks IFE UMKM Suka Sangrai}

\begin{tabular}{|c|c|c|c|c|}
\hline No & Faktor-Faktor Internal & Bobot & Rating & Skor \\
\hline \multicolumn{5}{|c|}{ Kekuatan } \\
\hline 1 & Kapabilitas dan kredibilitas owner di bidang roasting kopi & 0,081 & 4,0 & 0,324 \\
\hline 2 & Pelayanan terhadap konsumen sigap dan ramah & 0,086 & 4,0 & 0,344 \\
\hline 3 & Kualitas produk bagus dan terjamin & 0,096 & 3,0 & 0,288 \\
\hline 4 & Bahan baku yang digunakan terjamin kualitasnya & 0,083 & 4,0 & 0,332 \\
\hline 5 & Sudah mempunyai pelanggan tetap & 0,067 & 3,0 & 0,201 \\
\hline 6 & Produk mempunyai ciri khas & 0,082 & 4,0 & 0,328 \\
\hline 7 & Produk yang ditawarkan beragam & 0,085 & 3,5 & 0,297 \\
\hline 8 & Harga bersaing & 0,071 & 3,0 & 0,213 \\
\hline \multicolumn{5}{|c|}{ Kelemahan } \\
\hline 1 & $\begin{array}{l}\text { Sumber daya manusia masih terbatas (semua dilakukan oleh } \\
\text { owner) }\end{array}$ & 0,088 & 1,5 & 0,132 \\
\hline 2 & Kapasitas produksi masih terbatas & 0,100 & 1,5 & 0,150 \\
\hline 3 & Promosi penjualan belum maksimal & 0,088 & 2,0 & 0,17 \\
\hline & Belum ada admin khusus sosial media dan e-commerce & 0,064 & 1,5 & 0,096 \\
\hline & Total & $\mathbf{1 , 0 0 0}$ & 35,0 & 2,881 \\
\hline
\end{tabular}

Berdasarkan matriks IFE pada

Tabel 1, faktor yang menjadi kekuatan utama UMKM Suka Sangrai adalah pelayanan terhadap konsumen yang sigap dan ramah dengan perolehan skor 0,344. Sedangkan yang menjadi kelemahan utama UMKM Suka Sangrai adalah promosi penjualan yang belum maksimal dengan skor 0,17. Total Skor dari matriks IFE sejumlah 2,881 yang berarti bahwa faktor internal UMKM Suka Sangrai berada pada posisi kuat dalam memanfaatkan dan mengatasi kelemahan. 


\section{Hasil Analisis Matriks EFE}

Tabel 2. Hasil Analisis Matriks EFE

\begin{tabular}{llccc}
\hline No & \multicolumn{1}{c}{ Faktor-Faktor Eksternal } & Bobot & Rating & Skor \\
\hline & & & & 0,225 \\
\hline 1 & Perkembangan teknologi yang semakin maju & 0,075 & 3,0 & 0,420 \\
\hline 2 & Loyalitas pelanggan karena hubungan baik terus dijaga & 0,105 & 4,0 & 0,329 \\
\hline 3 & Perubahan gaya hidup masyarakat & 0,094 & 3,5 & 0,395 \\
\hline 4 & Kondisi perekonomian konsumen & 0,113 & 3,5 & 0,385 \\
\hline 5 & Pasar kopi masih terbuka luas & 0,110 & 3,5 & 0,440 \\
\hline 6 & Pertumbuhan kedai kopi & 0,110 & 4,0 & \\
\hline & & & 0,160 \\
\hline 1 & Harga bahan baku yang tidak stabil & 0,107 & 1,5 & 0,186 \\
\hline 2 & Bahan baku yang berkualitas dan kontinyu susah & 0,124 & 1,5 & 0,128 \\
\hline 3 & Perang harga & 0,064 & 2,0 & 0,136 \\
\hline 4 & Industri kopi mulai tidak secerah beberapa tahun ke belakang & 0,091 & 1,5 & $\mathbf{2 , 8 0 4}$ \\
\hline & Total & $\mathbf{1 , 0 0 0}$ & $\mathbf{2 8 , 0}$ &
\end{tabular}

Berdasarkan matriks EFE pada Tabel 2, faktor yang menjadi peluang utama UMKM Suka Sangrai adalah pertumbuhan kedai kopi yang meningkat dengan perolehan skor 0,440. Sedangkan yang menjadi ancaman utama UMKM Suka Sangrai adalah ketidakstabilan kontinuitas dan kualitas bahan baku dengan perolehan skor 0,186. Total skor dari matriks EFE sejumlah 2,804 yang menandakan UMKM Suka Sangrai berada pada posisi kuat dalam merespon peluang dan menghindari ancaman.
Hasil Analisis Matriks IE (InternalExternal)

Matriks $I E$ memiliki tiga implikasi strategi yang berbeda tergantung dari posisi perusahaan itu berada. Berdasarkan hasil skor pada Tabel 14 dan Tabel 15, total matriks IFE sebesar 2,881 dan matriks EFE sebesar 2,804. Setelah skor matriks IFE dan EFE diketahui, maka dari hasil total skor tersebut dapat ditentukkan posisi strategis UMKM Suka Sangrai melalui analisis matriks $I E$ yang terdapat pada Tabel 3. 
Tabel 3. Hasil Analisis Matriks IE (Internal-Eksternal) UMKM Suka Sangrai

Total Skor IFE

\begin{tabular}{|c|c|c|c|c|}
\hline \multirow{4}{*}{$\begin{array}{l}\text { Total Skor } \\
\text { EFE }\end{array}$} & \multirow[b]{2}{*}{ Tinggi 3,0 - 4,0 } & Kuat 3,0 - 4,0 & Sedang 2,0 - 2,99 & Lemah 1,0 - 1,99 \\
\hline & & $\begin{array}{c}\text { I } \\
\text { (Grow and Build) }\end{array}$ & $\begin{array}{c}\text { II } \\
\text { (Grow and Build) }\end{array}$ & $\begin{array}{c}\text { III } \\
\text { (Hold and Maintain) }\end{array}$ \\
\hline & Sedang 2,0 - 2,99 & $\begin{array}{c}\text { IV } \\
(\text { Grow and Build })\end{array}$ & $\begin{array}{c}\mathrm{V} \\
\text { (Hold and Maintain) }\end{array}$ & $\begin{array}{c}\mathrm{VI} \\
\text { (Harvest or Diverst) }\end{array}$ \\
\hline & Rendah 1,0 - 1,99 & $\begin{array}{c}\text { VII } \\
\text { (Hold and Maintain) }\end{array}$ & $\begin{array}{c}\text { VIII } \\
\text { (Harvest or Diverst) }\end{array}$ & $\begin{array}{c}\text { IX } \\
\text { (Harvest or Diverst) }\end{array}$ \\
\hline
\end{tabular}

Berdasarkan Tabel 3, diperlihatkan bahwa UMKM Suka Sangrai berada pada sel V (Hold and Maintain). Strategi yang cocok pada posisi sel ini bagi UMKM Suka Sangrai adalah strategi intensif (penetrasi pasar, pengembangan produk, dan pengembangan pasar).

\section{Hasil Analisis Matriks SWOT}

Penyusunan matriks SWOT ini dilakukan setelah melakukan analisis dan evaluasi faktor-faktor strategis berupa kekuatan, kelemahan, peluang, dan ancaman perusahaan. Analisis matriks SWOT pada UMKM Suka Sangrai dapat ditunjukkan pada Tabel 4. 


\section{Tabel 4. Hasil Analisis Matriks SWOT}

\begin{tabular}{|c|c|c|}
\hline & 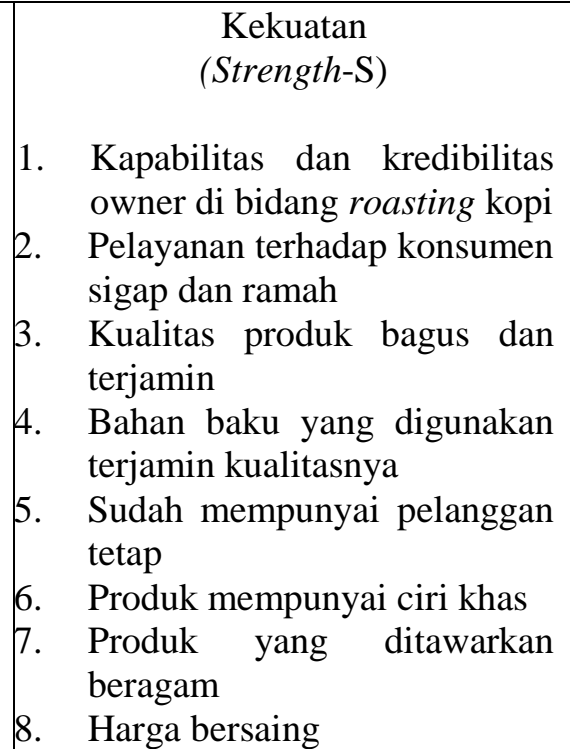 & $\begin{array}{l}\text { Kelemahan } \\
\qquad \text { (Weakness-W) } \\
\text { 1. Sumber daya manusia masih } \\
\text { terbatas (semua dilakukan oleh } \\
\text { owner) } \\
\text { 2. Kapasitas produksi masih } \\
\text { terbatas } \\
\text { 3. Promosi penjualan belum } \\
\text { maksimal } \\
\text { 4. Belum ada admin khusus sosial } \\
\text { media dan e-commerce }\end{array}$ \\
\hline $\begin{array}{l}\text { Peluang } \\
\text { (Opportunities-O) } \\
\text { 1. Perkembangan } \\
\text { teknologi yang } \\
\text { semakin maju } \\
\text { 2. Loyalitas pelanggan } \\
\text { karena hubungan baik } \\
\text { terus dijaga } \\
\text { 3. Perubahan gaya hidup } \\
\text { masyarakat } \\
\text { 4. Kondisi perekonomian } \\
\text { konsumen } \\
\text { 5. Pasar kopi masih } \\
\text { terbuka luas } \\
\text { 6. Pertumbuhan kedai } \\
\text { kopi }\end{array}$ & $\begin{array}{l}\text { Meningkatkan promosi } \\
\text { menggunakan media sosial } \\
\text { S3: Kualitas produk bagus dan } \\
\text { terjamin } \\
\text { S6: Produk mempunyai ciri khas } \\
\text { S7: Produk yang ditawarkan } \\
\text { beragam } \\
\text { O1: Perkembangan teknologi } \\
\text { yang semakin maju } \\
\text { O5: Pasar kopi masih terbuka luas } \\
\text { O6: Pertumbuhan kedai kopi }\end{array}$ & $\begin{array}{l}\quad \text { Menambahkan SDM bidang } \\
\quad \text { Sosial Media } \\
\text { W4: Belum ada admin khusus } \\
\text { sosial media dan e-commerce } \\
\text { W1: Sumber daya manusia masih } \\
\text { terbatas (semua dilakukan oleh } \\
\text { owner) } \\
\text { O1: Perkembangan teknologi yang } \\
\text { semakin maju }\end{array}$ \\
\hline $\begin{array}{l}\text { 1. Harga bahan baku } \\
\text { yang tidak stabil } \\
\text { 2. Bahan baku yang } \\
\text { berkualitas r dan } \\
\text { kontinyu susah } \\
\text { 3. Perang harga } \\
\text { 4. Industri kopi mulai } \\
\text { mengalami tidak } \\
\text { secerah beberapa tahun } \\
\text { ke belakang }\end{array}$ & $\begin{array}{l}\text { Strategi S-T } \\
\text { Mempertahankan kualitas produk } \\
\text { yang baik } \\
\text { S1: Kapabilitas dan kredibilitas } \\
\text { owner di bidang roasting kopi } \\
\text { S2: Pelayanan terhadap konsumen } \\
\text { sigap dan ramah } \\
\text { S6: Produk mempunyai ciri khas } \\
\text { S3: Kualitas produk bagus dan } \\
\text { terjamin } \\
\text { T3: Perang harga } \\
\text { T4: Industri kopi mulai } \\
\text { mengalami tidak secerah beberapa } \\
\text { tahun ke belakang }\end{array}$ & $\begin{array}{l}\text { Strategi W-T } \\
\text { Diversivikasi Produk } \\
\text { T3: Perang harga } \\
\text { T4: Industri kopi mulai mengalami } \\
\text { tidak secerah beberapa tahun ke } \\
\text { belakang } \\
\text { W1: Sumber daya manusia masih } \\
\text { terbatas (semua dilakukan oleh } \\
\text { owner) } \\
\text { W2: Kapasitas produksi masih } \\
\text { terbatas }\end{array}$ \\
\hline
\end{tabular}


Tabel 4 menunjukkan hasil analisis matriks SWOT yang menghasilkan 4 strategi alternatif bagi UMKM Suka Sangrai. Alternatif-alternatif strategi analisis SWOT adalah sebagai berikut:

1. Meningkatkan distribusi penjualan dengan mempromosikan menggunakan media sosial.

2. Menambahkan SDM dalam bidang media sosial.

3. Mempertahankan kualitas produk yang baik

4. Melakukan diversifikasi produk

\section{Hasil Analisis Matriks QSP}

Matriks QSP adalah alat analisis yang menentukan prioritas alternatif strategi yang dapat dijalankan perusahaan dari alternatif-alternatif strategi yang diperoleh dari hasil nalisis matriks SWOT (David, 2006). Analisis SWOT menghasilkan 4 alternatif strategi. Selanjutnya, diberikan nilai Attractive Score (AS) dengan mencocokan faktorfaktor strategis internal dan eksternal yang dapat mempengaruhi altertanif strategi. Setelah itu, dilakukan perkalian antara nilai AS dengan bobot rata-rata dari faktor kunci untuk menghasilkan Total Atrractive Score (TAS). Nilai TAS dijumlahkan secara vertikal untuk memperoleh jumlah total daya tarik atau Sum Total Attractiveness
Scores (STAS). Nilai STAS tertinggi akan menjadi prioritas strategi untuk dijalankan oleh pihak UMKM Suka Sangrai.

Hasil analisis matriks QSP berdasarkan urutan peringkat nilai STAS dari yang tertinggi adalah sebagai berikut:

1. Diversifikasi Produk UMKM Suka Sangrai (STAS 6,5869)

2. Meningkatkan promosi menggunakan media sosial (STAS 6,5278)

3. Mempertahankan kualitas produk yang baik (STAS 6,4569)

4. Menambahkan SDM bidang Sosial Media (STAS 6,44735)

Berdasarkan hasil analisis matriks QSP, dapat dilihat bahwa strategi yang menjadi prioritas yang harus segera dilaksanakan oleh UMKM Suka Sangrai adalah melakukan Diversifikasi Produk.

\section{KESIMPULAN DAN SARAN}

\section{Kesimpulan}

Berdasarkan hasil penelitian yang dilakukan pada UMKM Suka Sangrai, dapat disimpulkan beberapa hal berikut:

1. Strategi pengembangan yang dilakukan UMKM Suka Sangrai adalah mempererat hubungan konsumen melalui layanan yang selalu lebih baik dari sebelumnya untuk meningkatkan loyalitas konsumen dan kepuasan konsumen. 
2. Kekuatan utama UMKM Suka Sangrai adalah terletak di Pelayanan terhadap konsumen sigap dan ramah dengan nilai 0,344 dan dukungan kualitas bahan baku kopi yang terjamin. Sedangkan kelemahan utama adalah promosi penjualan yang belum maksimal dengan nilai 0.17 .

Peluang utama UMKM Suka Sangrai adalah pertumbuhan kedai kopi yang meningkat dengan nilai 0,440 . Sedangkan ancaman utama UMKM Suka Sangrai adalah ketidakstabilan kontinuitas dan kualitas bahan baku dengan perolehan skor 0,186 dikarenakan:

a. Harga bahan baku tidak stabil

b. Bahan baku yang berkualitas sulit didapatkan

c. Banyak pesaing menjatuhkan harga jual

3. Melakukan strategi pengembangan prioritas yang dapat diterapkan oleh UMKM Suka Sangrai, yaitu melakukan diversifikasi produk untuk memberikan konsumen beragam pilihan produk. Adapun diantaranya yang dapat dilakukan adalah :

a. Membuat beragam produk varian rasa houseblend kopi sangrai dengan kemasan kecil agar harga jual lebih terjangkau konsumen.

b. Membuat produk kopi sangrai yang sudah dihaluskan agar lebih mudah untuk diseduh.

c. Membuat produk dengan rasa yang beragam buah dengan mencapurkan biji kopi halus dengan perisa minuman seperti perisa mangga, perisa apel, dll.

\section{Saran}

Berdasarkan hasil penelitian yang telah disimpulkan dan melihat respon yang baik dari pihak UMKM Suka Sangrai, terdapat beberapa temuan yang dapat dijadikan saran untuk pengembangan UMKM Suka Sangrai. UMKM Suka Sangrai disarankan untuk :

a. Menjaga hubungan baik antara UMKM Suka Sangrai dan konsumennya.

b. Menjaga kualitas produk yang baik dan berkualitas

c. Memprioritaskan dan menerapkan prioritas strategi yang telah dirumuskan yaitu, melakukan diversifikasi produk untuk menambah pilihan produk bagi konsumen.

d. Menambah karyawan yang bertugas secara khusus dalam sosial media untuk memaksimalkan promosi dan 
penggunaan media sosial Instagram dan Tokopedia untuk memperluas jangkauan pasar UMKM Suka Sangrai.

\section{DAFTAR PUSTAKA}

David, Fred. 2006. Manajemen Strategi. Jakarta : Salemba Empat.

Halik, Abdul, Sri Budi Kasiyati, Endah Budiarti dan Ratnaningsih. 2015. Pengembangan Usaha Warung Kopi Di Desa Bungah dan Desa Lasem, Kabupaten Gresik. Jurnal Pengabdian LPPM Untag Surabaya Vol. 1, No. 02, hal 97-104.

Idrus, Muhammad. 2009. Metode Penelitian Ilmu Sosial, Pendekatan Kualitatif dan Kuantitatif. Jakarta : Erlangga.

Kementerian Pertanian Republik Indonesia. 2020. Konsumsi Kopi di Indonesia Tahun 2016-2020. Dalam web : www.pertanian.go.id. Diakses tanggal 6 Februari 2021.

Kementerian Pertanian Republik Indonesia. 2020. Produksi Kopi Menurut Provinsi di Indonesia 2016-2020. Dalam web : www.pertanian.go.id. Diakses tanggal 6 Februari 2021.

Pardian, Pandi, Dhany Esperanza, and Eliana Wulandari. 2012. "Strategi Pengembangan Usaha Oncom Terhadap Tenaga Kerja Pedesaan Guna Penguatan Ketahanan Pangan Dan Kesejahteraan Masyarakat.” Sosiohumaniora 14(1):38.

Pardian, Pandi Hapsari, Hepi Sukayat, Yayat. Stevia Development Strategy in the Village of Mekarsari Sub District Cikajang District Garut West Java Province. 2021. E3S Web of Conferences vol 249 (1-4)

Sugiyono, 2009. Metode Penelitian Kuantitatif, Kualitatif dan $R \& D$. Bandung: Alfabeta. 